\title{
A Gas Cell Based on Hollow-Core Photonic Crystal Fiber (PCF) and Its Application for the Detection of Greenhouse Gas (GHG): Nitrous Oxide $\left(\mathbf{N}_{\mathbf{2}} \mathbf{O}\right)$
}

\author{
Jonas K. Valiunas, ${ }^{1}$ Mario Tenuta, ${ }^{2}$ and Gautam Das ${ }^{1}$ \\ ${ }^{1}$ Department of Physics, Lakehead University, 955 Oliver Road, Thunder Bay, ON, Canada P7B 5E1 \\ ${ }^{2}$ Department of Soil Science, University of Manitoba, Winnipeg, MB, Canada R3T 3N2 \\ Correspondence should be addressed to Gautam Das; gdas@lakeheadu.ca
}

Received 15 September 2016; Accepted 3 November 2016

Academic Editor: Banshi D. Gupta

Copyright ( 2016 Jonas K. Valiunas et al. This is an open access article distributed under the Creative Commons Attribution License, which permits unrestricted use, distribution, and reproduction in any medium, provided the original work is properly cited.

The authors report the detection of nitrous oxide gas using intracavity fiber laser absorption spectroscopy. A gas cell based on a hollow-core photonic crystal fiber was constructed and used inside a fiber ring laser cavity as an intracavity gas cell. The fiber laser in the $1.55 \mu \mathrm{m}$ band was developed using a polarization-maintaining erbium-doped fiber as the gain medium. The wavelength of the laser was selected by a fiber Bragg grating (FBG), and it matches one of the absorption lines of the gas under investigation. The laser wavelength contained multilongitudinal modes, which increases the sensitivity of the detection system. $\mathrm{N}_{2} \mathrm{O}$ gas has overtones of the fundamental absorption bands and rovibrational transitions in the $1.55 \mu \mathrm{m}$ band. The system was operated at room temperature and was capable of detecting nitrous oxide gas at sub-ppmv concentration level.

\section{Introduction}

Trace gas sensing is a rapidly growing field of research and has received considerable attention, especially in the detection and quantification of greenhouse gases (e.g., $\mathrm{N}_{2} \mathrm{O}$ and $\mathrm{CO}_{2}$ ). It has also applications in noninvasive medical diagnostics, environmental monitoring, and homeland security.

Fertilizers used in agricultural fields are major sources of $\mathrm{N}_{2} \mathrm{O}$. The use of fertilizer will increase in the next few decades to meet the demand of food production as the global population increases. However, optimizing the efficiency with which fertilizers produce nutrients, combined with the design of new forms of fertilizers, can reduce their emission of $\mathrm{N}_{2} \mathrm{O}$. It is also important to note that the excess fertilizer drains into rivers and lakes due to rain or irrigation and polluting water bodies [1]. Further, the emission of $\mathrm{N}_{2} \mathrm{O}$ is spatially variable in soil because of soil factors that lead to the production, consumption, and mobility of the gas. Thus the ability to pinpoint "hot spots" of $\mathrm{N}_{2} \mathrm{O}$ emissions will allow one to mitigate soil factors. A farmer can regulate the use of fertilizer by measuring the concentration of $\mathrm{N}_{2} \mathrm{O}$ emitted from agricultural fields due to the application of fertilizer at different climate and soil conditions. This ability will facilitate the fertilizer industry's worldwide program of $4 \mathrm{R}$ (right fertilizer source, right rate, right time, and right replacement) Nutrient Stewardship management, which will in turn improve farm management and finally reduce greenhouse gas emissions.

The current widely used technologies (e.g., GC: Gas Chromatograph, FTIR: Fourier Transform Infrared spectroscopy, laser spectroscopy using a lead-salt detector cooled by liquid nitrogen or thermoelectric cooler, and cavity ring-down spectroscopy using a quantum cascade laser) to detect trace gases are complex and expensive [2]. Thus, a compact and cost-effective system that can operate at room temperature is in demand. A number of important gases (e.g., $\mathrm{CH}_{4}, \mathrm{NH}_{3}$, $\mathrm{C}_{2} \mathrm{H}_{2}, \mathrm{H}_{2} \mathrm{~S}, \mathrm{~N}_{2} \mathrm{O}$, and $\mathrm{CO}_{2}$ ) have overtones of the characteristic absorption (fundamental) and the combinations of the overtones bands in the near-infrared (NIR) region (1$2 \mu \mathrm{m})$ of the electromagnetic spectrum, which matches the emission spectrum of rare-earth (e.g., Erbium) doped fiber 
[3]. This makes it possible to use passive and active optical components available from telecom industries to develop a compact and cost-effective device for the detection of trace gases.

The greenhouse effect is caused by the absorption of infrared radiation (IR) from sunlight by gases such as nitrous oxide $\left(\mathrm{N}_{2} \mathrm{O}\right)$. Qualitatively, gases can be differentiated by their absorption lines, and, quantitatively, their concentrations can be determined by measuring the degree of absorption of light directed through a gas sample. The absorption of electromagnetic radiation (e.g., IR or NIR) by a gas is governed by the Beer-Lambert law [5]:

$$
\frac{I}{I_{0}}=\exp (-\alpha C L)
$$

where $I_{0}$ is the intensity of the incident optical radiation, $I$ is the transmitted optical intensity, $\alpha$ is the absorption coefficient of the gas molecules (an important parameter dependent on both the gas species and the wavelength of incident optical radiation), $C$ is the concentration of the absorbing molecules, and $L$ is the optical path length of the gas cell or absorption path length. In general, absorption spectroscopy (e.g., FTIR) makes use of incoherent light sources such as incandescent bulbs to generate IR radiation. These sources are essentially blackbody radiators, and complex optical components are required to collimate and direct the beam through the sample with narrow bandwidth. The sensitivity of the above devices is limited by the physical length of the gas cell. Highly sensitive spectroscopic techniques to enhance the absorption path length have been developed based on the laser, such as continuous-wave cavity ring-down spectroscopy (CW-CRDS) and intracavity laser absorption spectroscopy (ICLAS) [6]. The conventional CRDS technique involves measuring the decay time of the laser pulse injected into a high finesse cavity (Fabry-Perot or Ring configuration) that contains the gas sample, where the rate of decay of the pulse indicates the absorption by the gas sample. One can calculate the concentration of the gas sample from the decay time or the ring-down time. On the other hand, in ICLAS, the gas cell is used inside the laser cavity and no external laser is required. Both CRDS and ICLAS increase the effective absorption length by several times, compared to conventional FTIR systems [6]. As the path length is enhanced, the sensitivity of the device increases. Thus, combining advanced detection techniques with a gas cell with longer optical path length makes it possible to develop a very highly sensitive gas detection system.

In the present article, the authors report the design of a gas cell and its application for the detection of greenhouse gas, more specifically, nitrous oxide $\left(\mathrm{N}_{2} \mathrm{O}\right)$. A hollow-core photonic crystal fiber (PCF) was used to develop the gas cell and was incorporated as an intracavity gas cell in a fiber ring laser. The detailed structure of the laser cavity was described in [4]. The amplified spontaneous emission (ASE) light inside the laser cavity was used for the detection. In general, an erbiumdoped fiber gives a very wide $(\sim 100 \mathrm{~nm})$ ASE spectrum. A fiber Bragg grating (FBG) with peak wavelength close to one of the absorption lines was chosen and the system produced the laser at this wavelength. The wavelength was close to the lower side of the emission spectrum, where the absorption coefficient of $\mathrm{N}_{2} \mathrm{O}$ is higher, compared to that in the $\mathrm{C}$ and $\mathrm{L}$ band regions. $\mathrm{N}_{2} \mathrm{O}$ gas has three fundamental infrared active absorption bands: $v_{1}=1284.9 \mathrm{~cm}^{-1} \sim 7.8 \mu \mathrm{m} ; v_{2}=$ $588.8 \mathrm{~cm}^{-1} \sim 17 \mu \mathrm{m}$; and $v_{3}=2223.8 \mathrm{~cm}^{-1} \sim 4.5 \mu \mathrm{m}$. A number of articles, reporting results from different spectroscopic techniques such as Fourier Transform Infrared Absorption Spectroscopy (FTIR), Intracavity Laser Absorption Spectroscopy (ICLAS), and cavity ring-down spectroscopy (CRDS), identify transitions in the overtone bands for $\mathrm{N}_{2} \mathrm{O}$ gas [7-19].

In the system reported in this article, the rotational line in the $3 v_{3}$ overtone band $(\sim 1.52 \mu \mathrm{m}$ band $)$ available from HITRAN was used as a reference line to develop the sensing device [20]. The system based on the new gas cell was capable of detecting $\mathrm{N}_{2} \mathrm{O}$ at a concentrations level of sub-ppmv (parts per million by volume). The efficiency of the device has been explored using different lengths of hollow-core photonic crystal fiber (PCF) and spectroscopic techniques. The system based on the developed gas cell will be compact and costeffective compared to the system based on conventional gas cell, which has larger foot print.

\section{Development of the Gas Cell Using a Hollow-Core Photonic Crystal Fiber}

A gas cell that requires a very small amount $(\sim \mathrm{mL})$ of gas is important for high sensitivity laser absorption spectroscopy. In this respect, a hollow-core photonic crystal fiber (PCF) is a good candidate because of the high optical-path-to-samplevolume ratio [21-23]. In a PCF, light propagates through the hollow-core by photonic band gap effects, which occur due to the periodic distribution of air holes in the cladding [24]. The PCF is very attractive for applications in optical communications, because it shows very low attenuation, dispersion, and nonlinearity, bending loss, and it can also guide a fundamental mode over a wide spectral range without any leakage $[25,26]$. The idea of using a PCF for gas and liquid sensing is relatively new and there is scope to develop a new compact device using this fiber [27-29]. An all-fiber gas cell has been proposed and demonstrated for gas detection [30]. Recently a number articles have been published on gas sensors based on PCF in CRD spectroscopy $[31,32]$, wavelength modulation spectroscopy (WMS) [33], ICAS [34], and Raman spectroscopy [35]. Most of the gas cells developed using a PCF are designed to detect a particular chemical or gas [31, 36-39]. In [40-43], the dynamics of gas flow in PCF, which determine the filling and evacuation time for the PCF-based gas cell, have been investigated. In order to reduce the filling and evacuation time and thus increase the response time of the detection system, researchers used a number of techniques, such as splicing the PCF to a normal single-mode fiber and allowing the gas sample to fill the core at a higher pressure [28], drilling holes on the surface of PCF so that gas can diffuse faster [4446], using specially designed mechanical splices [47, 48], and finally using a specially designed fiber [49]. It is important to 


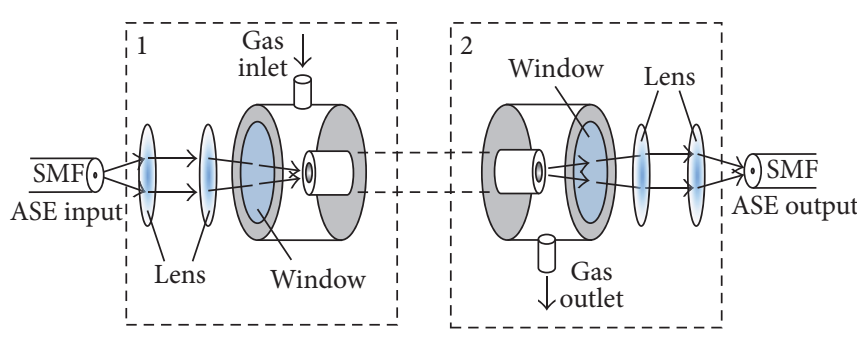

(a)

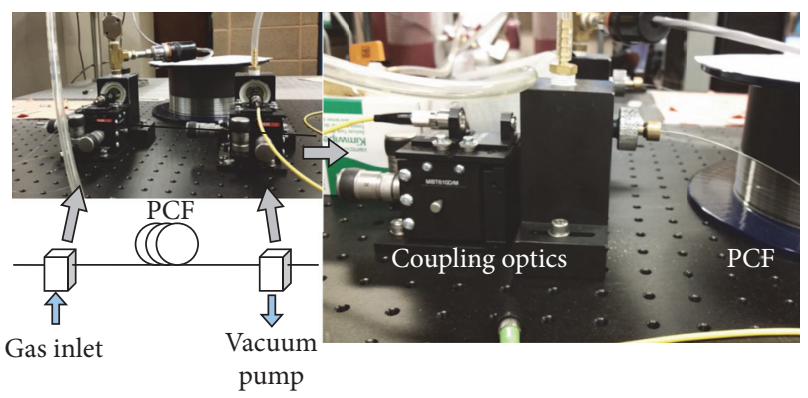

(b)

FIGURE 1: (a) Schematic of the gas cell based on hollow-core photonic crystal fiber and (b) gas cell developed in the Photonics Lab. PCF: hollow-core photonic crystal fiber.

note that the commercially available gas cell based on PCF does not allow one to change the fiber if required.

Figure 1 shows the gas cell developed using a hollow-core photonic crystal fiber [HC19-1550, core diameter: $20 \mu \mathrm{m}$ ] from NKT Photonics to detect trace gases. The system has two lens system assemblies (1 and 2), together with two solid aluminum blocks of dimensions $2^{\prime \prime} \times 2^{\prime \prime} \times 4^{\prime \prime}$. A very small hole was drilled inside the steel block, so that the volume of the gas inside was very small-only a few $\mathrm{mL}$. The steel block in assembly 1 is connected to a gas inlet and that in assembly 2 is connected to a pump (note: the system was developed so that both assemblies can be connected to either a gas inlet or a vacuum pump). The hollow-core fiber was evacuated using the pump. The vacuum level was maintained at $\sim 0.2 \mathrm{mb}$, when evacuated from one side only. It was important to adjust the optimum pressure difference between assembly 1 and assembly 2 for a steady gas flow through the hollow-core PCF. The time to evacuate a $20 \mathrm{~m}$ long PCF was approximately 80 minutes, which led to a slow response time for the system. The experiment was repeated with $40 \mathrm{~m}$ of PCF. The increased fiber length caused a longer gas evacuation and filling time. To improve the filling time, the gas was allowed to diffuse from one end while other side was connected to the vacuum pump, and, after some time, gas was allowed to diffuse from both ends.

The front of each block was fitted with an AR (antireflection) coated quartz window and the back side was fitted with fiber coupling components. The light was coupled into (and out of) the PCF through the quartz window. The top of block 2 was fitted with a gas on/off switch and a vacuum gauge (Figure 1(b)). To eliminate leakage through the fiber chuck at the back of the block, a specially designed O-ring and cap developed in house was used (Figure 2). Figure 1(b) shows how the PCF was inserted inside the aluminum block using the custom-designed connector. The advantage of this system was that it could maintain a constant vacuum level $(\sim 0.2 \mathrm{mb})$ at one end of the fiber while allowing gas to diffuse through the other end. During the filling process, the fiber was evacuated from both sides of the PCF for a certain amount of time, and then one end of the PCF was maintained at a lower pressure and the other end was connected to a Tedlar bag filled with $\mathrm{N}_{2} \mathrm{O}$ gas at a particular concentration. Two gas tanks, one with $\mathrm{N}_{2} \mathrm{O}$ and another with $\mathrm{N}_{2}$ from Praxair,

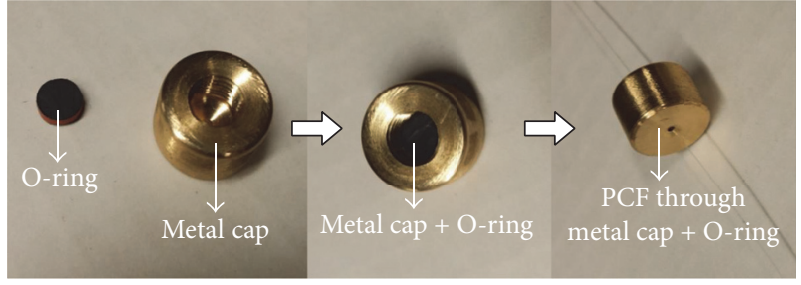

FIgURE 2: O-ring and metal cap to secure the PCF air tight.

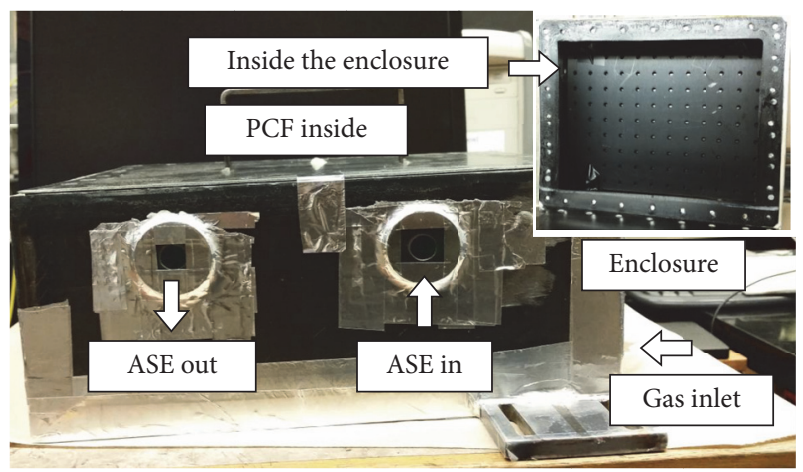

FIgURE 3: Gas cell based on a steel rectangular box.

Canada, and a mass flow controller from Omega were used to prepare specific mixtures of gas. Both tanks were connected directly to $100 \mathrm{~nm}$ filters in order to remove any dust particles contained in the gas. The optical fiber at the input (and output) and lenses in each assembly were mounted on a three-axis stage. As shown in Figure 1(a), one lens collimated the beam and the other one focused the collimated beam on the tip of the PCF through the quartz window.

In addition to the cell shown in Figure 1, the authors have developed another gas cell (Figure 3), which consists of a steel rectangular box with a lid. The PCF of desired length was placed inside the box. The steel box was fitted with a gas inlet and an outlet. An optical bread board was also placed inside the box to make it possible to mount optical components inside the box. Light was coupled into (and out of) the PCF through the antireflection (AR) coated quartz windows (as shown in Figure 3). The fibers for ASE (or light) In/Out were 


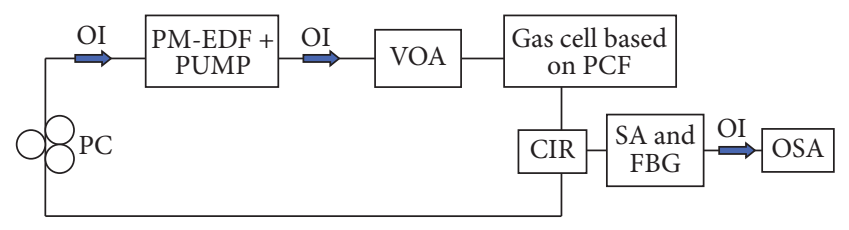

FIGURE 4: Schematic of the experimental setup for the detection of trace gas. PUMP: pump laser; PM-EDF: polarization-maintaining erbium-doped fiber; VOA: variable optical attenuator; SA: saturable absorber; FBG: fiber Bragg grating; OSA: optical spectrum analyzer; CIR: polarization independent optical circulator; PC: polarization controller; and OI: polarization independent optical isolator [4].

mounted on three-axis translation stages with a combination of lenses as described for the previous cell (Figure 1). The PCF inside the box was mounted on fiber clamps [HFF003, Thorlabs] close to the quartz windows. Gas in the steel box was evacuated from one end first and then the gas under investigation was allowed to enter from the other end. It was possible to evacuate and fill the PCF from both ends as it was inside the box with both ends open. This process required a long time to fill and evacuate the PCF completely. To find the filling and evacuation time for a particular length of PCF, the output was monitored by observing absorption lines of $1 \% \mathrm{C}_{2} \mathrm{H}_{2}$ in the $\mathrm{C}$ band region, where they are very strong. The disadvantage for this system was the long response time, which was due to the large volume of the gas cell compared to the volume of the PCF. The advantage of the gas cell is that one can drill holes along the length on the surface of PCF so that gas can diffuse faster inside the core of the fiber and thus decrease the response time of the system $[45,46]$. In this article, the authors present experimental data based on the gas cell described in Figure 1 for $\mathrm{N}_{2} \mathrm{O}$.

Figure 4 shows the schematic of the experimental setup used for the detection of $\mathrm{N}_{2} \mathrm{O}$. The gas cell (Figure 1) described in the previous section was used inside the cavity. The unidirectional resonant ring cavity consists of a polarization-maintaining erbium-doped fiber (PM-EDF); a variable optical attenuator (VOA) to adjust the loss in the cavity; an unpumped PM-EDF as the saturable absorber (SA); a fiber Bragg grating (FBG) of reflectivity $85.16 \%$, peak wavelength $\sim 1522.22 \mathrm{~nm}$, and bandwidth of $0.168 \mathrm{~nm}$, where the peak wavelength of the FBG was close to $\mathrm{P}$ (12) rotational absorption line (Figure 5(a)) of $\mathrm{N}_{2} \mathrm{O}$; and an all-fiber polarization controller to control the polarization state of the light inside the cavity. The detailed cavity design and advanced detection technique developed by the authors were described in [4]. The presence of polarization-maintaining gain fiber and SA increases the stability of the laser wavelength.

The advantages of the detection system are (i) the laser generated by the system contains a multilongitudinal mode, which increased the sensitivity of detection of gases at lower concentrations; (ii) the system is capable of operating at room temperature (most of the currently commercially available systems require cooling below room temperature); (iii) standard optical components available from telecom industries were used for developing the device; (iv) a gas cell based on hollow-core photonic crystal fiber makes the system compact and suitable for conversion into a hand-held device; and (v) the system can be used to detect various other gases (e.g., $\mathrm{NH}_{3}, \mathrm{H}_{2} \mathrm{~S}$, etc.) simply by changing the FBG.

\section{Results and Discussions}

Figure 5(a) shows the rotational lines in the $3 v_{3}$ overtone band for $\mathrm{N}_{2} \mathrm{O}$, obtained using Spectral Calculator, GATS [10, 20]. Although $\mathrm{N}_{2} \mathrm{O}$ possesses relatively strong absorption lines at $\sim 1522 \mathrm{~nm}$, the gain-coefficient of erbium-doped fiber is much lower compared to that in the $\mathrm{C}$ and $\mathrm{L}$ band regions. Further, erbium-doped fiber is a homogeneous gain medium at normal temperatures and the lasing wavelength is determined by the local maximum of the gain curve. For a ring cavity without a FBG lasing occurs in the C or L band. Figure 5(b) shows an ICLAS system developed using the gas cell described in Figure 3 . The cavity loss could be changed by adjusting the variable optical attenuator (VOA), which was adjusted to obtain an almost flat (60\% inversion) spectrum in the $\mathrm{C}$ and $\mathrm{L}$ band regions. Once the system has reached this condition (called balanced condition), any small change in the cavity loss will switch the laser from the $\mathrm{C}$ band to the $\mathrm{L}$ band or vice versa. Figure 6(a) shows the switching of the laser wavelength from the $\mathrm{C}$ band to the $\mathrm{L}$ band after a slight adjustment (i.e., increasing the loss in the $\mathrm{C}$ band region) of the VOA. In order to obtain very high sensitivity in detection using ASE inside the laser cavity, it is important to adjust the VOA (and thus the inversion level) in such a way that a very small change in attenuation can switch the laser between two bands when the laser operates under threshold conditions. A gas sample inside the ICLAS cavity also provide attenuation (due to absorption), which is similar to the VOA. Figure 6(b) shows the switching of the laser line from the $\mathrm{C}$ band to the $\mathrm{L}$ band once the gas cell (Figure 3: steel box) was filled with $0.5 \%$ of $\mathrm{C}_{2} \mathrm{H}_{2}$. A few absorption lines are also visible in the $\mathrm{C}$ band, because the gas has many strong absorption lines in this region. The absorption coefficient for $\mathrm{N}_{2} \mathrm{O}$ is lower ( $\sim$ three orders of magnitude) than the $\mathrm{C}_{2} \mathrm{H}_{2}$ in the $\mathrm{C}$ band. Thus, it was not possible to take advantage of ASE light available inside the cavity to detect $\mathrm{N}_{2} \mathrm{O}$ using the system as shown in Figure 5(b). The OSA (ANDO optical spectrum analyzer) spectra in the manuscript were collected using LABVIEW program (wavelength resolution: $0.005 \mathrm{~nm}$ and intensity resolution: $0.001 \mathrm{dBm}$ ) and each spectrum presented is the average of 10 scans.

The setup in Figure 4 was developed in order to take advantage of the ASE light inside the cavity in the $\sim 1522 \mathrm{~nm}$ band, where $\mathrm{N}_{2} \mathrm{O}$ has high absorption compared to that in the $\mathrm{C}$ and L bands [4]. The FBG wavelength was chosen so that the peak wavelength is close to one of the absorption lines, $\mathrm{P}(12)$ rotation line in the $3 v_{3}$ band [Figure 5(a)], and does not interfere with the absorption lines due to the presence of $\mathrm{CO}_{2}$ and $\mathrm{H}_{2} \mathrm{O}$ (Figure 7). Two different lengths $(20 \mathrm{~m}$ and $40 \mathrm{~m}$ ) of PCF were used to make the gas cell, and the corresponding lengths of the unidirectional ring cavity were approximately $40 \mathrm{~m}$ and $60 \mathrm{~m}$, respectively [including the length of the PCF]. The system produced a stable multilongitudinal mode laser output at room temperature with a maximum separation of $\sim 3 \mathrm{MHz}$ for $40 \mathrm{~m}$ long PCF. A laser oscillating in multiple 


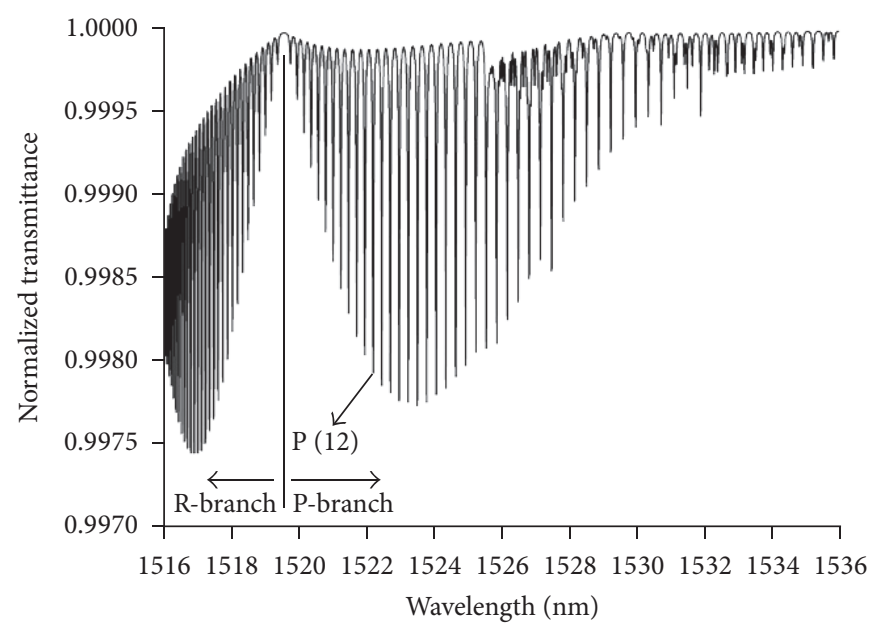

(a)

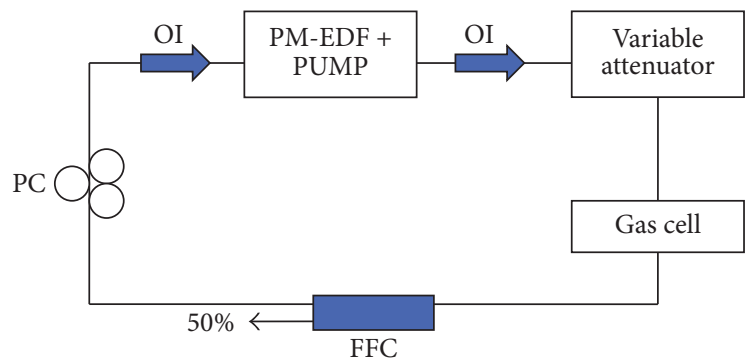

(b)

Figure 5: (a) Theoretical rotational transition for $\mathrm{N}_{2} \mathrm{O}$ in the $3 v_{3}$ band obtained using Spectral Calculator (GATS). (b) Experimental setup to study ICAS using ASE light inside the cavity.

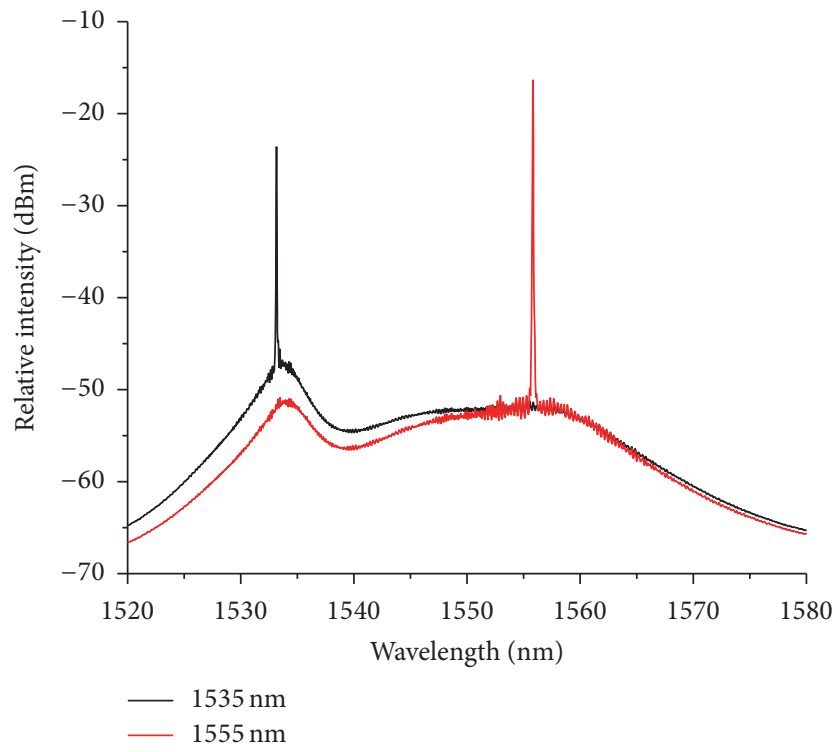

(a)

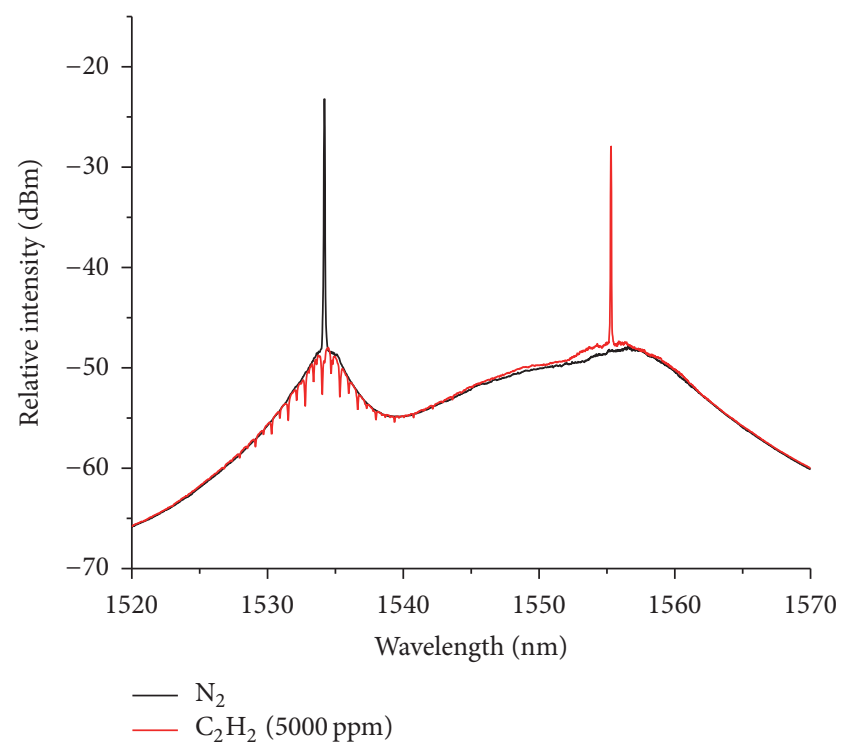

(b)

Figure 6: Output of the system obtained from the OSA (a) adjusting the VOA and (b) using a hollow-core fiber (HC19-1550, NKT) of length $6 \mathrm{~m}$ as gas cell inside the cavity filled with $0.5 \%$ acetylene gas. The absorption lines are clearly visible in the $\mathrm{C}$ band.

longitudinal modes is susceptible to mode hopping, but the small length of SA inside the cavity was able to eliminate the mode hopping at normal room temperature [50,51]. Baev et al. reported properties of multilongitudinal mode lasers and their application in ICLAS [52]. It was found that a multilongitudinal mode laser provides very high sensitivity in ICLAS, if the homogeneously broadened gain bandwidth is larger than the absorption linewidth. In fact, the number of photons in a mode that matches the narrow band absorption line will decrease following the Beer-Lambert law. The ICAS produces a very good absorption spectrum if the absorption line of the gas sample is larger than the longitudinal mode separation
[52]. In the present system, the absorption linewidth was larger than the separation between two longitudinal modes, so many longitudinal modes were superimposed within the absorption line. Further, Haensch et al. [53] also showed an increase of absorption sensitivity by a factor of $10^{5}$ due to the presence of a number of oscillating modes.

The experimental setup described in Figure 4 produced a multilongitudinal mode laser wavelength, which was selected by the FBG. The laser was kept under the threshold condition, so that the wavelengths related to the ASE light close to the laser wavelength were also close to the threshold condition. Thus, the photons corresponding to ASE light inside the 


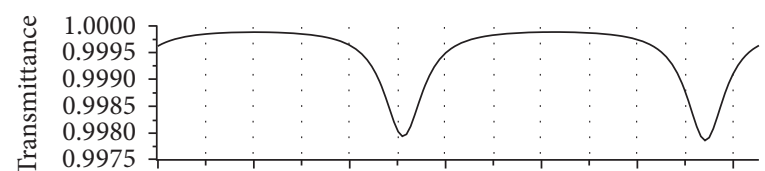

$-\mathrm{N}_{2} \mathrm{O}$

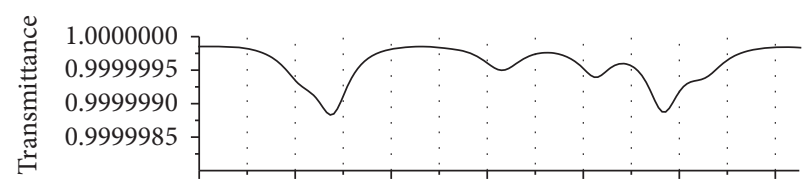

$-\mathrm{CO}_{2}$

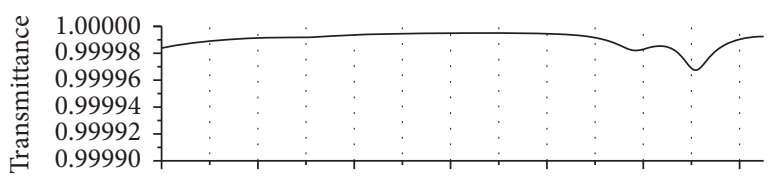

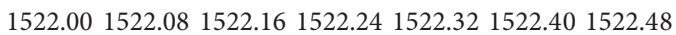

Wavelength $(\mathrm{nm})$

$-\mathrm{H}_{2} \mathrm{O}$

FIGURE 7: Theoretical absorption spectra obtained using Spectral Calculator (GATS: HITRAN 2012).

cavity circulated multiple times and enhanced the effective path length of the cavity. In turn, the sensitivity of detection was also enhanced due to the large absorption path length.

Figure 8 shows the absorption spectra from the direct absorption of the $10 \% \mathrm{~N}_{2} \mathrm{O}$ (Praxair, Canada, certified concentration of $\mathrm{N}_{2} \mathrm{O}: 10 \%+\mathrm{N}_{2}$ balance) gas using a $40 \mathrm{~m}$ and $20 \mathrm{~m}$ long PCF after subtracting the reference gas $\mathrm{N}_{2}$, obtained using the gas cell shown in Figure 1. The gas was allowed to diffuse through one end and the other end was maintained at constant vacuum level. The ASE from the PM$\mathrm{EDF}\left[I_{P}=75 \mathrm{~mA}\right]$ was used as the input light for the direct absorption spectroscopic (DAS) measurement (note: the laser cavity was not closed). The output obtained was monitored using the OSA. The absorption lines of the gas disappeared after a few cycles of evacuation and filling with $\mathrm{N}_{2}$. The hollow-core (20 micron diameter) of the PCF was surrounded by small, micron-order holes. The longer evacuation time was due to the presence of these gas-filled smaller holes. It is anticipated that most of the laser power is confined to the core and the effect of absorption due to gas inside the surrounding small holes is minimal or not significant. It is also possible to obtain the DAS spectrum by using a tunable laser.

Figure 9(a) shows the transmission spectra of the experimental setup described in Figure 4 with the reference gas $\mathrm{N}_{2}$ (Praxair, Canada, Research Grade, Nitrogen 6.0) and $\mathrm{N}_{2} \mathrm{O}$ (Praxair, Canada, certified concentration of $\mathrm{N}_{2} \mathrm{O}: 10 \%+\mathrm{N}_{2}$ balance and $0.1 \%+\mathrm{N}_{2}$ balance) with $40 \mathrm{~m}$ PCF for the gas cell. The absorption spectrum in Figure 9(b) was obtained by subtracting the spectra for $\mathrm{N}_{2} \mathrm{O}(10 \%)$ and $\mathrm{N}_{2}$ shown in Figure 9(a). The system described in Figure 4 was operating under threshold condition $\left(I_{P}=147.5 \mathrm{~mA}\right)$. It is to be noted that that the gas cell was flushed with $\mathrm{N}_{2}$ before and after the

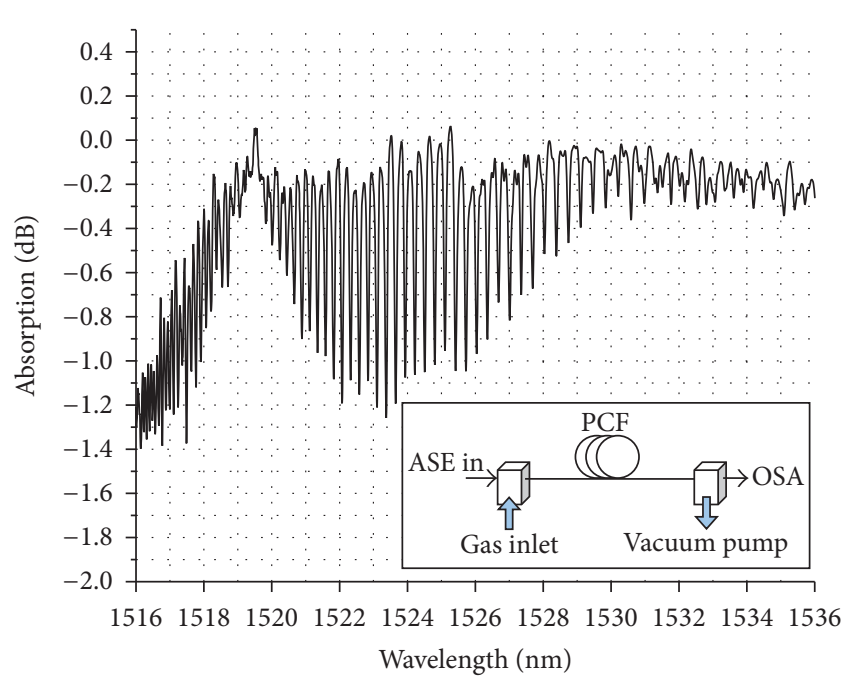

(a)

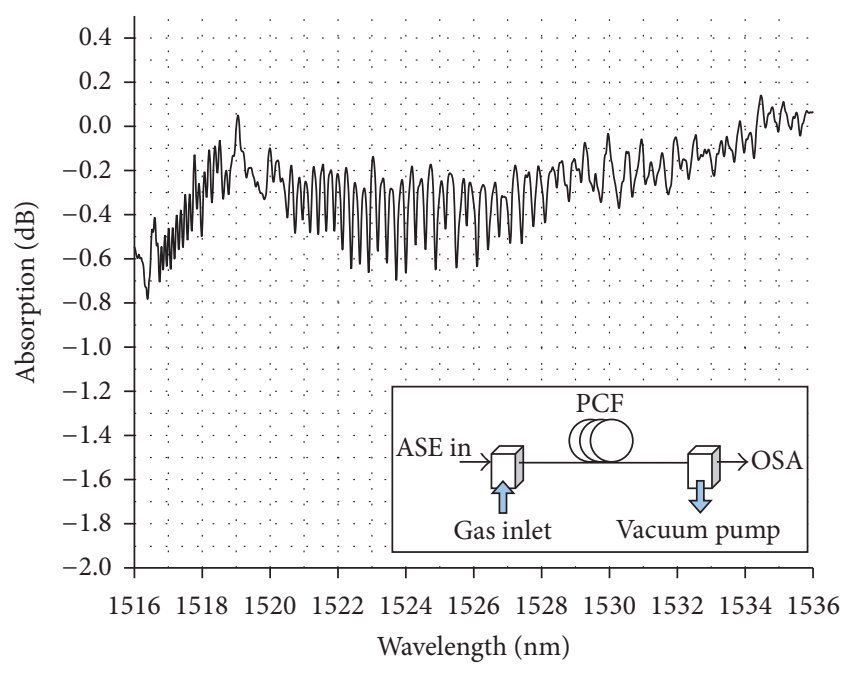

(b)

Figure 8: Direct Absorption Spectra of $\mathrm{N}_{2} \mathrm{O}$ gas after subtracting the $\mathrm{N}_{2}$ gas spectrum as background for (a) $40 \mathrm{~m}$ and (b) $20 \mathrm{~m}$ of PCF, respectively. The inset in the figures shows the schematic of the gas cell shown in Figure 1.

scanning with $\mathrm{N}_{2} \mathrm{O}$ gas. The experiment was repeated with $20 \mathrm{~m}$ long PCF. Figure 10 shows output spectra obtained using a $20 \mathrm{~m}$ long PCF as the gas cell inside the system in Figure 4, for $10 \%$ and $0.1 \% \mathrm{~N}_{2} \mathrm{O}$, respectively.

It is clear from the spectra in Figure 8, obtained using DAS and in Figures 9 and 10, using ICLAS, that the specificity and sensitivity of detection increase at the FBG location. Further, the application of a FBG eliminates any overlap with absorption lines due to other gases in the mixture. In the present case, the authors used the absorption line corresponding to the $\mathrm{P}(12)$ line of $\mathrm{N}_{2} \mathrm{O}$. The experiments were performed with lower concentrations of $\mathrm{N}_{2} \mathrm{O}$ gas. The minimum concentration the system could detect with $40 \mathrm{~m}$ long PCF after a longer evacuation and filling time ( $\sim 4$ hours) was $\sim 500 \mathrm{ppbv}$ 


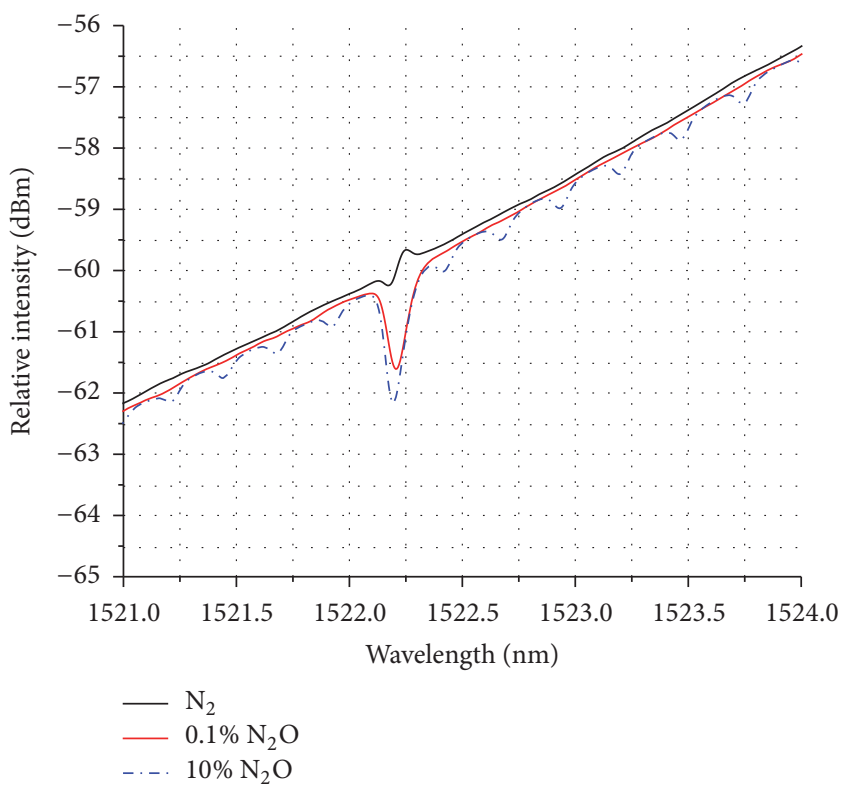

(a)

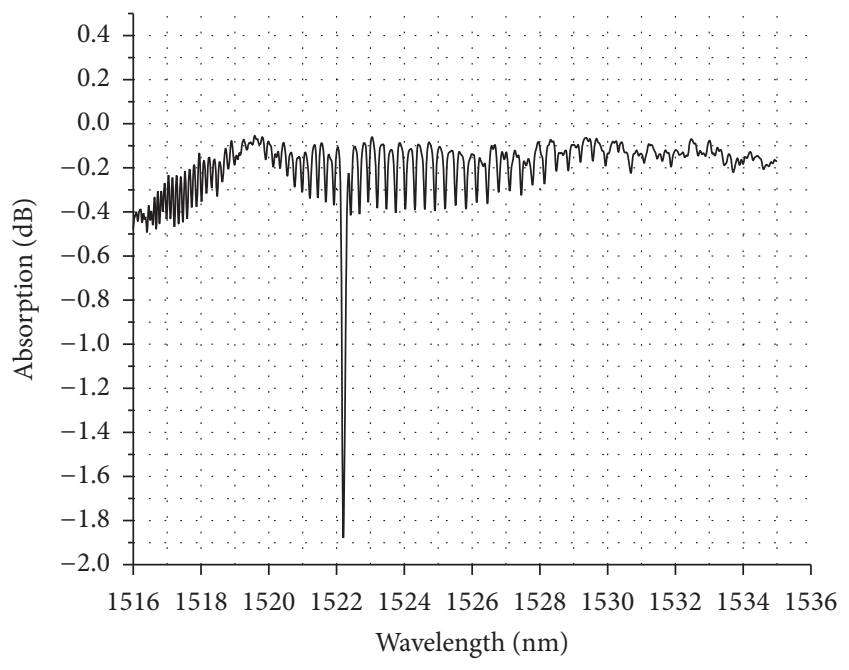

(b)

Figure 9: (a) Absorption Spectra of $\mathrm{N}_{2} \mathrm{O}$ gas at two different concentrations. (b) Absorption spectrum of $10 \% \mathrm{~N}_{2} \mathrm{O}$ after subtracting the $\mathrm{N}_{2}$ gas spectrum as background for $40 \mathrm{~m}$ long PCF.

(Figure 11; Praxair, Canada, certified concentration of $\mathrm{N}_{2} \mathrm{O}$ : $520 \mathrm{ppbv}+\mathrm{N}_{2}$ balance).

\section{Conclusions}

The authors have presented two gas cells based on hollowcore photonic crystal fiber for the detection of nitrous oxide gas. The gas cell was incorporated inside a laser cavity as an intracavity gas cell. At present, the evacuation and filling time for the gas through the PCF is too long for use where fast response is important. The responsivity can be increased by reducing gas evacuation and filling times. In addition,

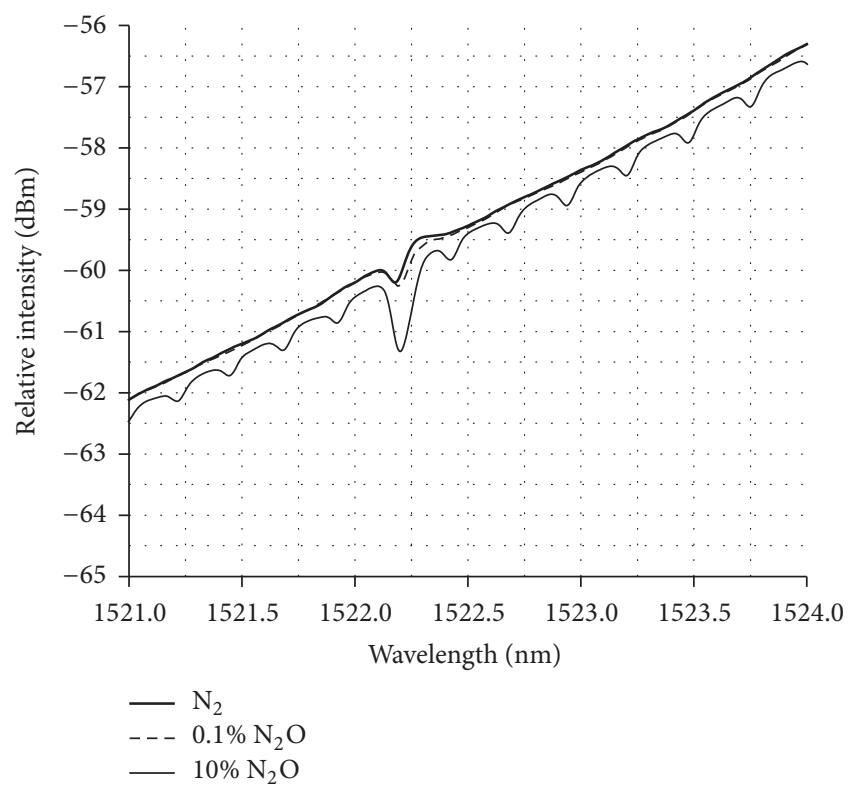

(a)

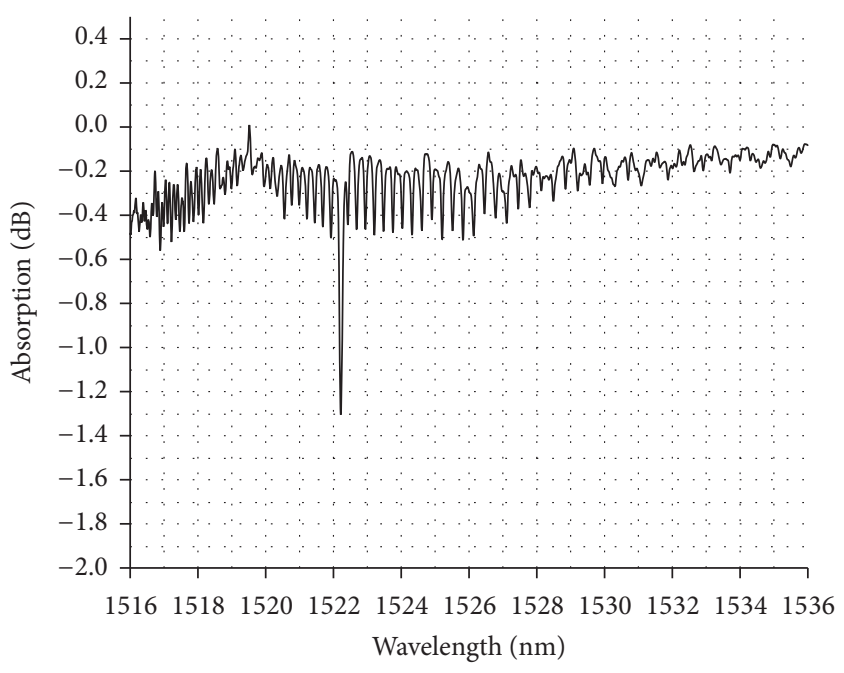

(b)

Figure 10: (a) Absorption Spectra of $\mathrm{N}_{2} \mathrm{O}$ gas at two different concentrations. (b) Absorption spectrum of $10 \% \mathrm{~N}_{2} \mathrm{O}$ after subtracting the $\mathrm{N}_{2}$ gas spectrum as background for $20 \mathrm{~m}$ long PCF.

the laser cavity supported multilongitudinal modes, which increased the sensitivity further. The system is capable of operating at room temperature and over a wide set of wavelengths. One can select the gas absorption line of any trace gas by using a tunable FBG. The system can be used as a hand-held device.

\section{Competing Interests}

The authors declare that there are no competing interests regarding the publication of this paper. 


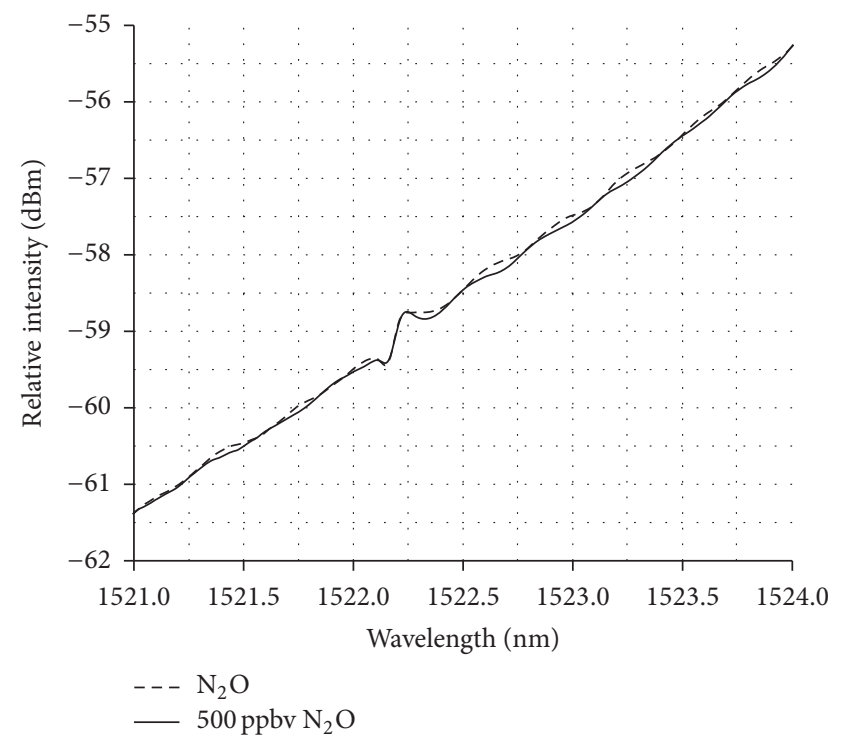

FIgURE 11: Absorption spectrum of 500 ppbv $\mathrm{N}_{2} \mathrm{O}$ gas for $40 \mathrm{~m}$ long PCF.

\section{Acknowledgments}

The authors acknowledge the financial support of the Natural Sciences and Engineering Research Council of Canada, Agrium Inc., and Canada Foundation for Innovation. Authors also acknowledge Professor George Stewart, University of Strathclyde, UK, for helpful suggestions.

\section{References}

[1] F. A. Phillips, R. Leuning, R. Baigent, K. B. Kelly, and O. T. Denmead, "Nitrous oxide flux measurements from an intensively managed irrigated pasture using micrometeorological techniques," Agricultural and Forest Meteorology, vol. 143, no. 12, pp. 92-105, 2007.

[2] A. J. Glenn, M. Tenuta, B. D. Amiro, S. E. Maas, and C. WagnerRiddle, "Nitrous oxide emissions from an annual crop rotation on poorly drained soil on the Canadian Prairies," Agricultural and Forest Meteorology, vol. 166-167, pp. 41-49, 2012.

[3] G. Whitenett, G. Stewart, H. Yu, and B. Culshaw, "Investigation of a tuneable mode-locked fiber laser for application to multipoint gas spectroscopy," Journal of Lightwave Technology, vol. 22, no. 3, pp. 813-819, 2004.

[4] J. K. Valiunas, G. Stewart, and G. Das, "Detection of Nitrous Oxide $\left(\mathrm{N}_{2} \mathrm{O}\right)$ at Sub-ppmv using intracavity absorption spectroscopy," IEEE Photonics Technology Letters, vol. 28, no. 3, pp. 359-362, 2016.

[5] N. Arsad, M. Li, G. Stewart, and W. Johnstone, "Intra-cavity spectroscopy using amplified spontaneous emission in fiber lasers," Journal of Lightwave Technology, vol. 29, no. 5, Article ID 5677567, pp. 782-788, 2011.

[6] G. Stewart, P. Shields, and B. Culshaw, "Development of fibre laser systems for ring-down and intracavity gas spectroscopy in the near-IR," Measurement Science \& Technology, vol. 15, no. 8, pp. 1621-1628, 2004.

[7] E. K. Plyler, E. D. Tidwell, and A. G. Maki, "Infrared absorption spectrum of nitrous oxide $\left(\mathrm{N}_{2} \mathrm{O}\right)$ from $1830 \mathrm{~cm}^{-1}$ to $2270 \mathrm{~cm}^{-1}$,"
Journal of Research of the Natonal Bureau of Standards-A. Physics and Chemistry, vol. 68, no. 1, pp. 79-86, 1963.

[8] A. Campargue, D. Permogorov, M. Bach et al., "Overtone spectroscopy in nitrous oxide," The Journal of Chemical Physics, vol. 103, no. 14, pp. 5931-5938, 1995.

[9] F. G. Wienhold, H. Fischer, and G. W. Harris, "Fast response tunable diode laser spectroscopy for trace gas flux measurements," Infrared Physics and Technology, vol. 37, no. 1, pp. 67-74, 1996.

[10] R. A. Toth, "Line positions and strengths of $\mathrm{N}_{2} \mathrm{O}$ between 3515 and $7800 \mathrm{~cm}^{-1}$," Journal of Molecular Spectroscopy, vol. 197, no. 2, pp. 158-187, 1999.

[11] G. Weirauch, A. A. Kachanov, A. Campargue, M. Bach, M. Herman, and J. Vander Auwera, "Refined investigation of the overtone spectrum of nitrous oxide," Journal of Molecular Spectroscopy, vol. 202, no. 1, pp. 98-106, 2000.

[12] A. M. Parkes, A. R. Linsley, and A. J. Orr-Ewing, "Absorption cross-sections and pressure broadening of rotational lines in the $3 v_{3}$ band of $\mathrm{N}_{2} \mathrm{O}$ determined by diode laser cavity ringdown spectroscopy," Chemical Physics Letters, vol. 377, no. 3-4, pp. 439-444, 2003.

[13] E. Bertseva, A. Campargue, V. I. Perevalov, and S. A. Tashkun, "New observations of weak overtone transitions of $\mathrm{N}_{2} \mathrm{O}$ by ICLAS-VeCSEL near $1.07 \mu \mathrm{m}$," Journal of Molecular Spectroscopy, vol. 226, no. 2, pp. 196-200, 2004.

[14] L. Wang, V. I. Perevalov, S. A. Tashkun, B. Gao, L.-Y. Hao, and S.-M. Hu, "Fourier transform spectroscopy of $\mathrm{N}_{2} \mathrm{O}$ weak overtone transitions in the 1-2 $\mu \mathrm{m}$ region," Journal of Molecular Spectroscopy, vol. 237, no. 2, pp. 129-136, 2006.

[15] A. W. Liu, S. Kassi, P. Malara et al., "High sensitivity CW-cavity ring down spectroscopy of $\mathrm{N}_{2} \mathrm{O}$ near $1.5 \mu \mathrm{m}$ (I)," Journal of Molecular Spectroscopy, vol. 244, no. 1, pp. 33-47, 2007.

[16] A. W. Liu, S. Kassi, V. I. Perevalov, S. A. Tashkun, and A. Campargue, "High sensitivity CW-cavity ring down spectroscopy of $\mathrm{N}_{2} \mathrm{O}$ near $1.5 \mu \mathrm{m}$ (II)," Journal of Molecular Spectroscopy, vol. 244, no. 1, pp. 48-62, 2007.

[17] H.-Y. Ni, K.-F. Song, V. I. Perevalov et al., "Fourier-transform spectroscopy of ${ }^{14} \mathrm{~N}^{15} \mathrm{~N}^{16} \mathrm{O}$ in the $3800-9000 \mathrm{~cm}^{-1}$ region and global modeling of its absorption spectrum," Journal of Molecular Spectroscopy, vol. 248, no. 1, pp. 41-60, 2008.

[18] K.-F. Song, A.-W. Liu, H.-Y. Ni, and S.-M. Hu, "Fouriertransform spectroscopy of ${ }^{15} \mathrm{~N}^{14} \mathrm{~N}^{16} \mathrm{O}$ in the $3500-9000 \mathrm{~cm}^{-1}$ region," Journal of Molecular Spectroscopy, vol. 255, no. 1, pp. 2431, 2009.

[19] B. Gao, C.-Y. Wang, Y. Lu, A.-W. Liu, and S.-M. Hu, "Highresolution infrared spectroscopy of ${ }^{15} \mathrm{~N}_{2}^{16} \mathrm{O}$ in the 3500-9000 $\mathrm{cm}^{-1}$ region," Journal of Molecular Spectroscopy, vol. 259, no. 1, pp. 20-25, 2010.

[20] L. S. Rothman, I. E. Gordon, Y. Babikov et al., "The HITRAN2012 molecular spectroscopic database," Journal of Quantitative Spectroscopy \& Radiative Transfer, vol. 130, pp. 450, 2013.

[21] A. Lancia, "Hollow core fiber guides as gas analysis cells for laser spectroscopy," in Optical Sensors and Microsystems: New Concepts, Materials, Technologies, pp. 235-240, 2000.

[22] T. Ritari, H. Ludvigsen, and J. C. Petersen, "Photonic bandgap fibers in gas detection," Spectroscopy, vol. 20, no. 4, pp. 30-34, 2005.

[23] J. P. Parry, B. C. Griffiths, N. Gayraud et al., "Towards practical gas sensing with micro-structured fibres," Measurement Science \& Technology, vol. 20, no. 7, Article ID 075301, 2009. 
[24] J. C. Knight, J. Broeng, T. A. Birks, and P. St. J. Russell, "Photonic band gap guidance in optical fibers," Science, vol. 282, no. 5393, pp. 1476-1478, 1998.

[25] F. Benabid and P. S. J. Russell, "Hollow core photonic crystal fibers: progress and prospects," in Proceedings of The SPIE: Photonic Crystal Materials and Devices III, vol. 5733, pp. 176189, 2005.

[26] M. N. Petrovich, F. Poletti, and D. J. Richardson, "Control of modal properties and modal effects in air guiding photonic bandgap fibres," in Proceedings of the 11th International Conference on Transparent Optical Networks (ICTON '09), pp. 1-4, IEEE, Azores, Portugal, July 2009.

[27] M. N. Petrovich, A. van Brakel, F. Poletti et al., "Microstructured fibres of sensing applications," in Proceedings of the Photonic Crystals and Photonic Crystal Fibers for Sensing Applications, vol. 6005 of Proceedings of SPIE, pp. 78-92, 2005.

[28] T. Ritari, J. Tuominen, H. Ludvigsen et al., "Gas sensing using air-guiding photonic bandgap fibers," Optics Express, vol. 12, no. 17, pp. 4080-4087, 2004.

[29] A. Duval, M. Lhoutellier, J. B. Jensen et al., "Photonic crystal fiber based antibody detection," in Proceedings of the IEEE $3 \mathrm{rd}$ Conference on Sensors (SENSORS '04), vol. 3, pp. 1222-1225, Vienna, Austria, October 2004.

[30] F. Benabid, F. Couny, J. C. Knight, T. A. Birks, and P. S. J. Russell, "Compact, stable and efficient all-fibre gas cells using hollowcore photonic crystal fibres," Nature, vol. 434, no. 7032, pp. 488491, 2005.

[31] A. van Brakel, C. Jauregui, T. T. Ng et al., "Cavity ring-down in a photonic bandgap fiber gas cell," in Proceedings of the Conference on Lasers and Electro-Optics, 2008 and 2008 Conference on Quantum Electronics and Laser Science (CLEO/QELS '08), IEEE, San Jose, Calif, USA, May 2008.

[32] D. Munzke, M. Böhm, and O. Reich, "Gaseous oxygen detection using hollow-core fiber-based linear cavity ring-down spectroscopy," Journal of Lightwave Technology, vol. 33, no. 12, pp. 2524-2529, 2015.

[33] F. Magalhães, J. P. Carvalho, L. A. Ferreira, F. M. Araújo, and J. L. Santos, "Methane detection system based on wavelength modulation spectroscopy and hollow-core fibres," in Proceedings of the IEEE SENSORS, pp. 1277-1280, Lecce, Italy, October 2008.

[34] H. W. Zhang, Y. Lu, L. C. Duan, Z. Q. Zhao, W. Shi, and J. Q. Yao, "Intracavity absorption multiplexed sensor network based on dense wavelength division multiplexing filter," Optics Express, vol. 22, no. 20, pp. 24545-24550, 2014.

[35] D. S. Bomse and M. N. Ediger, "Simultaneous detection of multiple gases by raman spectroscopy with hollow-core fibers," in Proceedings of the Conference on Lasers and Electro-Optics (CLEO '14), San Jose, Calif, USA, June 2014.

[36] A. M. Cubillas, J. M. Lazaro, O. M. Conde, M. N. Petrovich, and J. M. Lopez-Higuera, "Gas sensor based on photonic crystal fibres in the $2 v_{3}$ and $v_{2}+2 v_{3}$ vibrational bands of methane," Sensors, vol. 9, no. 8, pp. 6261-6272, 2009.

[37] A. M. Cubillas, J. Hald, and J. C. Petersen, "High resolution spectroscopy of ammonia in a hollow-core fiber," Optics Express, vol. 16, no. 6, pp. 3976-3985, 2008.

[38] C. Y. Tao, H. M. Wei, and W. L. Feng, "Photonic crystal fiber in-line Mach-Zehnder interferometer for explosive detection," Optics Express, vol. 24, no. 3, pp. 2806-2817, 2016.

[39] X. Li, J. Liang, S. Lin, Y. Zimin, Y. Zhang, and T. Ueda, "NIR spectrum analysis of natural gas based on hollow-core photonic bandgap fiber," IEEE Sensors Journal, vol. 12, no. 7, pp. 2362$2367,2012$.
[40] J. Henningsen and J. Hald, "Dynamics of gas flow in hollow core photonic bandgap fibers," Applied Optics, vol. 47, no. 15, pp. 2790-2797, 2008.

[41] I. Dicaire, J.-C. Beugnot, and L. Thévenaz, "Analytical modeling of the gas-filling dynamics in photonic crystal fibers," Applied Optics, vol. 49, no. 24, pp. 4604-4609, 2010.

[42] Y. L. Hoo, W. Jin, H. L. Ho, J. Ju, and D. N. Wang, "Gas diffusion measurement using hollow-core photonic bandgap fiber," Sensors and Actuators B: Chemical, vol. 105, no. 2, pp. 183186, 2005.

[43] I. Dicaire, J. C. Beugnot, and L. Thevenaz, "Optimized conditions for gas light interaction in photonic crystal fibres," in Proceedings of the 4th European Workshop on Optical Fibre Sensors, vol. 7653 of Proceedings of SPIE, p. 76530L, Porto, Portugal, September 2010.

[44] M. Amanzadeh, E. Sheridan, S. M. Aminossadati, M. S. Kizil, and W. P. Bowen, "Microfabricated hollow core fibres for gas sensing using wavelength modulation spectroscopy," in Proceedings of the Conference on Lasers and Electro-Optics (CLEO '13), San Jose, Calif, USA, June 2013.

[45] C. J. Hensley, D. H. Broaddus, C. B. Schaffer, and A. L. Gaeta, "Photonic band-gap fiber gas cell fabricated using femtosecond micromachining," Optics Express, vol. 15, no. 11, pp. 6690-6695, 2007.

[46] A. van Brakel, C. Grivas, M. N. Petrovich, and D. J. Richardson, "Micro-channels machined in microstructured optical fibers by femtosecond laser," Optics Express, vol. 15, no. 14, pp. 8731-8736, 2007.

[47] R. Dhawan, M. M. Khan, N. Panwar, U. Tiwari, R. Bhatnagar, and S. C. Jain, "A low loss mechanical splice for gas sensing using Hollow-Core Photonic Crystal Fibre," Optik, vol. 124, no. 18, pp. 3671-3673, 2013.

[48] J. M. Lazaro, A. M. Cubillas, M. Silva-Lopez, O. M. Conde, M. N. Petrovich, and J. M. Lopez-Higuera, "Methane sensing using multiple-coupling gaps in hollow-core photonic bandgap fibers," in Proceedings of the 19th International Conference on Optical Fibre Sensors, Perth, Australia, 2008.

[49] S. H. Kassani, J. Park, Y. Jung, J. Kobelke, and K. Oh, "Fast response in-line gas sensor using C-type fiber and Ge-doped ring defect photonic crystal fiber," Optics Express, vol. 21, no. 12, pp. 14074-14083, 2013.

[50] J. K. Valiunas and G. Das, "Tunable single-longitudinal-mode high-power fiber laser," International Journal of Optics, vol. 2012, Article ID 475056, 6 pages, 2012.

[51] P. J. Moore, Z. J. Chaboyer, and G. Das, "Tunable dualwavelength fiber laser," Optical Fiber Technology, vol. 15, no. 4, pp. 377-379, 2009.

[52] V. M. Baev, T. Latz, and P. E. Toschek, "Laser intracavity absorption spectroscopy," Applied Physics B, vol. 69, no. 3, pp. 171-202, 1999.

[53] T. Haensch, A. L. Schawlow, and P. E. Toschek, "Ultrasensitive response of a CW dye laser to selective extinction," IEEE Journal of Quantum Electronics, vol. 8, no. 10, pp. 802-804, 1972. 


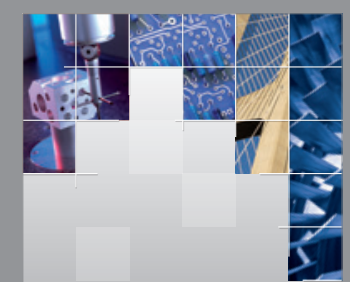

\section{Enfincering}
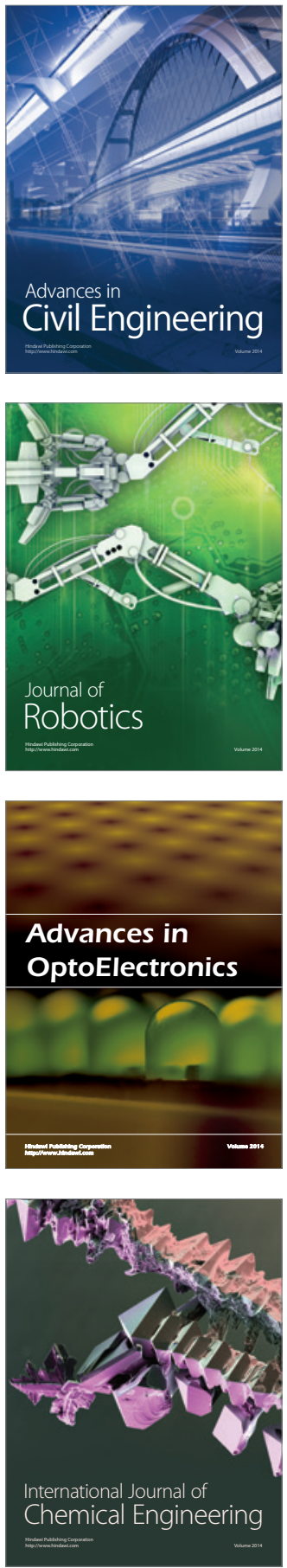

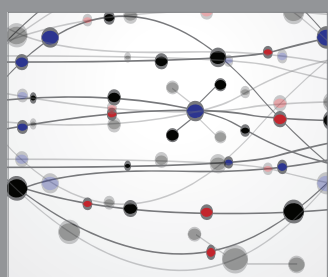

The Scientific World Journal

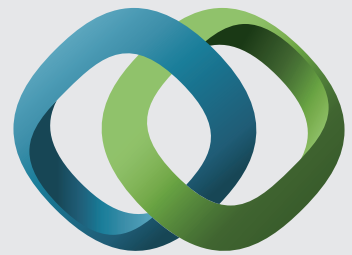

\section{Hindawi}

Submit your manuscripts at

http://www.hindawi.com
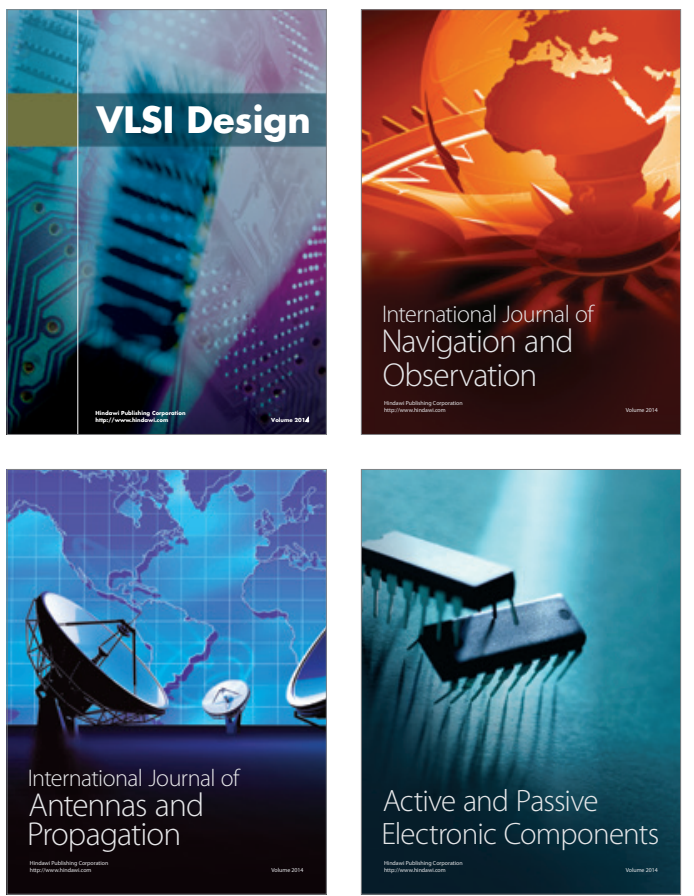
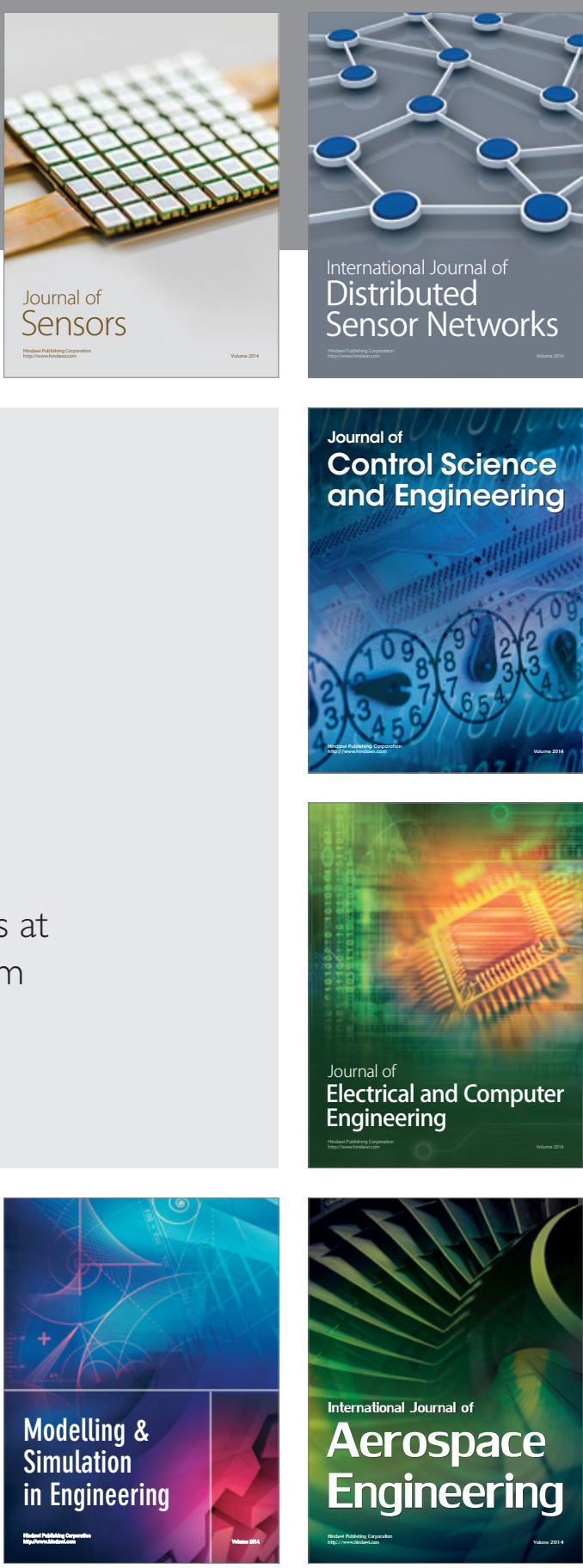

International Journal of

Distributed

Sensor Networks

Journal of

Control Science

and Engineering
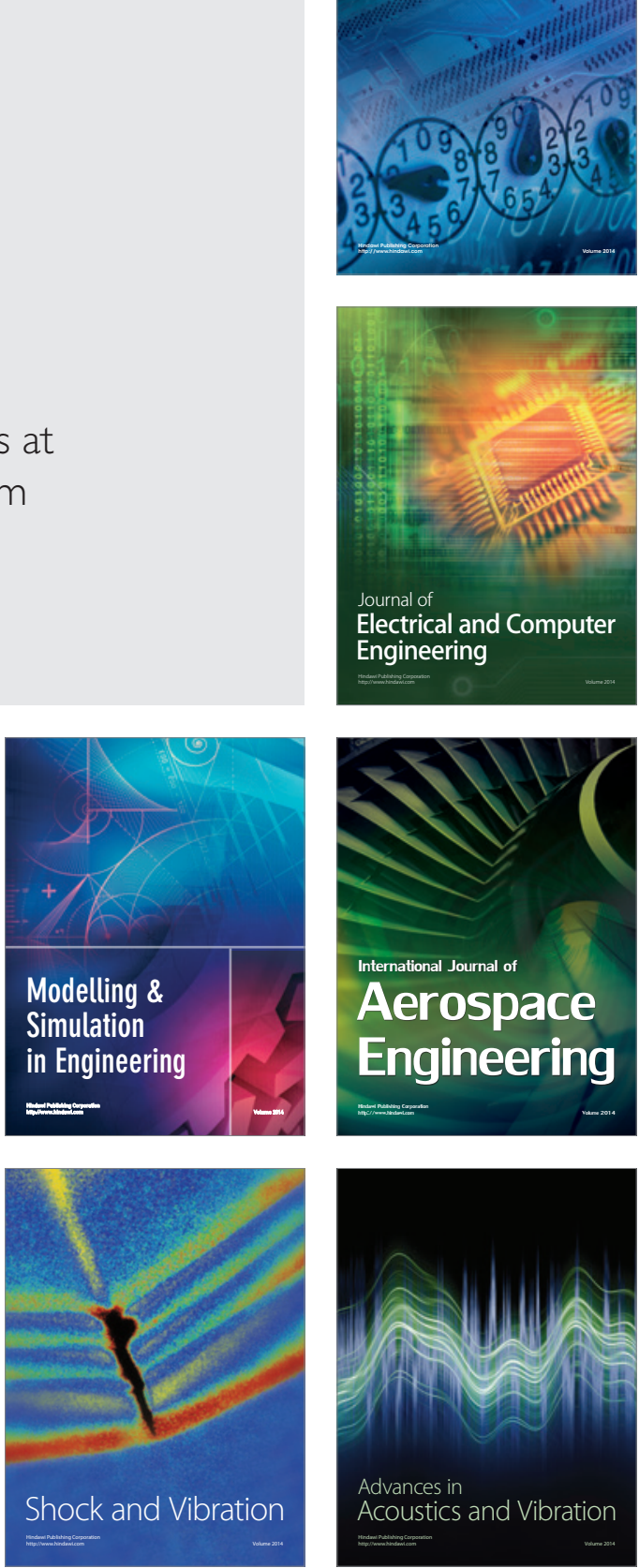